\title{
Differentiation between drug-type, fibre-type and intermediate-type in cannabis samples: HPLC-UV versus GC-FID
}

\author{
Kian Kadkhodaei ${ }^{1}$ Nina Biei ${ }^{1}$ Esther Caelles Vidiella ${ }^{2}$ Pamela Osmenaj $^{3}$ Giuseppe Cannazza $^{3}$ Martin G. Schmid $^{1^{*}}$ \\ ${ }^{1}$ Department of Pharmaceutical Chemistry, Institute of Pharmaceutical Sciences, University of Graz, Graz, Austria \\ ${ }^{2}$ Departamento de Farmacia y Tecnología Farmacéutica, y Fisicoquímica, Facultat de Farmacia, Universitat de Barcelona, Barcelona, Spain \\ ${ }^{3}$ Dipartimento di Scienze della Vita, Facoltà di Farmacia, Università degli studi di Modena Reggio Emilia, Modena, Italy
}

\section{Check for updates}

Correspondence to: Martin G. Schmid, Department of Pharmaceutical Chemistry, Institute of Pharmaceutical Sciences, University of Graz, Universitätsplatz 1, A-8010 Graz, Austria;

E-mail: martin.schmid@uni-graz.at

Received: November 11, 2020;

Accepted: January 23, 2021;

Published: January 26, 2021

Citation: Kadkhodaei K, Biei N, Vidiella EC, et al. Differentiation between drug-type, fibre-type and intermediate-type in cannabis samples: HPLC-UV versus GC-FID. J Pharm Biopharm Res, 2021, 2(2): 161-168.

https://doi.org/10.25082/JPBR.2020.02.003

Copyright: (c) 2021 Martin G. Schmid, et al. This is an open access article distributed under the terms of the Creative Commons Attribution License, which permits unrestricted use, distribution, and reproduction in any medium, provided the original author and source are credited.

\begin{abstract}
Cannabis sativa is known to be the most abused illegal drug worldwide. To date it is not only used as a medicine but has been established as a lifestyle product. The most relevant phytocannabinoids represent the ingredients delta-9-tetrahydrocannabinol ( $\Delta^{9}$-THC) and cannabidiol (CBD), whereby only $\Delta^{9}$-THC shows a psychoactive effect. Since 2017 , the so-called CBD-hemp containing CBD as main ingredient is distributed in many countries as a legal alternative. In these products, $\Delta^{9}$-THC must not exceed a certain percentage. It is hardly possible to differentiate between THC-hemp and CBD-hemp presenting a major challenge for authorities. Therefore, there is the need to develop fast and efficient analysis methods to distinguish between fibre-type, drug-type and intermediate-type cannabis products. The aim of this study was to compare two simple and inexpensive HPLC-UV and GC-FID methods for their ability to quantify phytocannabinoids in dried cannabis plant material. For this purpose, a set of 37 fresh and dried cannabis samples randomly chosen from seizures of Austrian police was subject to complementary quantification of $\Delta^{9}$-THC and CBD. After having taken into account decomposition of certain phytocannabinoids, the result of this quantitative study showed good correlation between HPLC-UV and GC-FID regardless of quantifying cannabis leaves or buds.
\end{abstract}

Keywords: Cannabinoids, $\Delta^{9}$-THC, THCA, CBD, CBDA, HPLC-UV, GC-FID

\section{Introduction}

In 2018, Cannabis sativa was named the medicinal plant of the year in Austria by the Herbal Medicinal Products Platform Austria (HMPPA). Also previously, the plant was extremely fashionable. Cultivation and use go back thousands of years. At this time, of course, the ingredients were still unknown. During the past 40 years, Turner et al. and Elsohly et. al. reported 490 constituents between the years 1980 and 2005 [1,2].

The most prominent two active ingredients in Cannabis sativa are the phytocannabinoids delta-9-tetrahydrocannabinol ( $\Delta^{9}$ - THC) and cannabidiol (CBD), whereby the latter one still does not count as an official drug substance. Also, $\Delta^{9}$-THC leads to a psychoactive effect, CBD does not. Therefore, drug-type cannabis is also very promizing for illegal use. According to the European Drug Report 2019, it is estimated that around 96 million people in the European Union tried out drugs once in their lifetime. Among them, about 91.2 million people once consumed cannabis [3]. On the other hand, since the year 2018 when the plant has been named the medicinal plant of the year, fibre-type and intermediate-type cannabis were strongly promoted. The difference between a THC-containing hemp and a CBD-containing hemp can be neither distinguished macroscopically, microscopically nor olfactoric. Moreover, legislation is different in most countries leading to problems, e.g. when consumers import or export cannabis.

As an example, in Austria, cannabis is subject to the Narcotic Substance Act, whereby both ingredients $\Delta^{9}$-THC and tetrahydrocannabinolic acid (THCA) are listed as scheduled compounds. In plant material, the sum of $\Delta^{9}$-THC and THCA must not exceed $0.3 \%$. Cultivation for the purpose of obtaining addictive substances, the acquisition, processing, possession, sale, transfer and import, export and transit are prohibited by law. However, the legislation on cultivation is not described clearly. On the one hand, it is allowed to possess cannabis plants as ornamental plants, on the other hand it must not be brought to flower.

As a consequence, the number of so-called "Hemp shops" not only in Austria but also in other European countries is strongly increasing. Cannabis plants are traded as cuttings with the 
recommendation that they must only be kept as an ornamental plant. Also dealers and consumers can always rely on possessing CBD hemp, trusting in a $\Delta^{9}$-THC content below $0.3 \%$, but there is no quality control. The huge number of seized samples is a big challenge for authorities, because often, it is not clear whether a drug-type, fibre-type and intermediate-type cannabis is present. Intermediate-type cannabis is a result of crossing drug-type and fibre-type. Moreover, Hemp shops do not sell cuttings only, they also offer CBD preparations as oils, honeys, flowers and drops. In all these cases, mostly the content of cannabinoids of these products is unknown.

National forensic analyses of 'low-THC' cannabis herb in Italy, Luxembourg and Austria revealed that they were indeed low in $\Delta^{9}$-THC. However, some products sold as "high in CBD" have been found to contain levels of $\Delta^{9}$-THC that may cause unexpected intoxication of users [4].

In order to differ between hemp preparations, the content of $\Delta^{9}$-THC and CBD can be determined by various chromatographic methods. In literature, several methods for analysis of cannabinoids in Cannabis sativa have been published, including high-performance thin-layer chromatography (HPTLC) [5,6], supercritical fluid chromatography (SFC) [7-9], gas chromatography (GC) $[9,10]$ and high-performance liquid chromatography (HPLC) [11-15]. However, due to the decarboxylation of cannabidiolic acid (CBDA) and THCA at high temperature, it is not possible to detect these corresponding acids by GC (Figure 1).

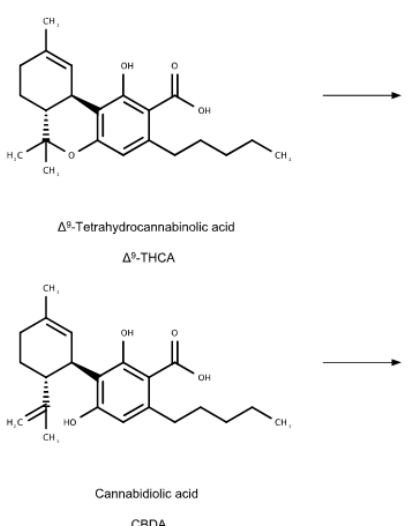

CBDA
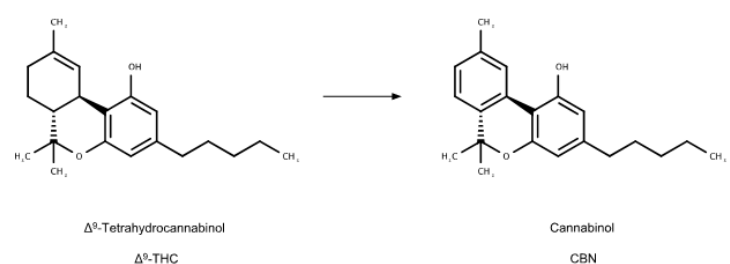

$\triangle \triangle^{\circ} \mathrm{THC}$

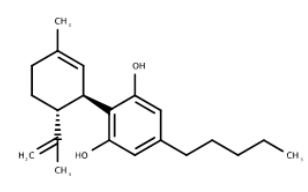

CBD

Figure 1 Decarboxylation and oxidation of cannabinoids

Recently, Shimadzu brought up a U-HPLC equipment devoted to separation and quantification of cannabinoids. The company offers a package named "Hemp Analyzer" along with standards and the method.

The aim of this research was to circumvent cost intensive detectors such as mass selective detection and to compare GC-FID and HPLC-UV as two very common techniques to quantify CBD and $\Delta^{9}$-THC. Because of produced heat, with GC-FID the sum of $\Delta^{9}$-THC and THCA as well as CBD and CBDA is obtained. With HPLC, no heat is produced while measurement, this is why CBD and $\Delta^{9}$-THC and their corresponding acids can be quantified separately. Occasionally it is important to know the average proportion of $\Delta^{9}$-THC and CBD to their corresponding acids, since the acids do not decompose following a strict rule rather than influence by temperature, light and surface. According earlier findings, for THCA and $\Delta^{9}$-THC this proportion has been found 92:8 [15]. However, for CBD and CBDA, no data were found.

\section{Material and methods}

\subsection{Chemicals and solutions}

Phosphoric acid (85\%), n-hexane, ethyl acetate, acetonitrile (ACN) (VWR, Darmstadt, Germany), triethylamine (Sigma-Aldrich, St. Louis, MO, USA) and triphenylamine (Alfa Aesar, Karlsruhe, Germany), were of analytical grade. Dronabinol ( $\Delta^{9}$-THC), THCA and CBDA standards were obtained from THC Pharm GmbH (Frankfurt/Main, Germany). CBD standard was a generous gift from G.L. Pharma (Lannach, Austria). Millipore water was bought from Fisher Scientific (Loughborough, UK). All cannabis samples were seized by Austrian Police in fresh and dry condition. 


\subsection{Chromatographic conditions}

\subsubsection{Chromatographic conditions for HPLC analysis}

An Agilent 1100 Series Liquid Chromatograph equipped with an autosampler, diode array detector and column oven was used. HPLC analysis were performed on a LiChrospher ${ }^{\circledR} 100$ RP-18 $(5 \mu \mathrm{m})$ LiChroCART ${ }^{\circledR}$ 125-4 column from Merck KGaA (Darmstadt, Germany). Sample determination and measurements were performed at a flow rate of $2 \mathrm{ml} / \mathrm{min}$ and an injection volume of $25 \mu \mathrm{l}$. Column oven was set to $40^{\circ} \mathrm{C}$. The UV detection was set to $210 \mathrm{~nm}$. Data were evaluated with Chemstation Rev. B. 04.03 [16] (Agilent Technologies, Waldbronn, Germany) software.

Mobile phase was prepared by mixing triethylammoniumphosphate buffer $\mathrm{pH} 2.66$ and ACN in the required ratios. Afterwards the solution was degassed in the ultrasonic bath (Vevor, CA, United States) for $5 \mathrm{~min}$.

\subsubsection{Chromatographic Conditions for GC analysis}

An Agilent 7890B Gas Chromatograph was used for GC-FID analysis. Separation was carried out on a HP 5 ( $0.32 \mathrm{~mm}$ x $30 \mathrm{~m} ; 0.25 \mu \mathrm{m}$ film thickness) column. Helium was used as a carrier gas $(1.0 \mathrm{ml} / \mathrm{min}$ flow rate).

The oven program starts at a temperature of $160^{\circ} \mathrm{C}$ and remains at this temperature for 30 sec. The temperature ramps at a rate of $10^{\circ} \mathrm{C} / \mathrm{min}$ to $280^{\circ} \mathrm{C}$, then temperature rises again within $1.5 \mathrm{~min}$ to a final maximum of $300^{\circ} \mathrm{C}$. The post run lasts $2 \mathrm{~min}$. The total run time is $14 \mathrm{~min}$. Data were evaluated with Agilent ChemStation software Rev.B.04.03-SP2.

\subsection{Sample preparation}

\subsubsection{Sample preparation for HPLC analysis}

Air-dried cannabis samples were grounded with a Bosch ${ }^{\circledR}$ MKM6003 coffee grinder (Bosch, Stuttgart, Germany). $50 \mathrm{mg}$ of the grounded samples were extracted in $25 \mathrm{ml}$ solvent (nhexane/ethyl acetate (9:1) for $20 \mathrm{~min}$ in ultrasonic bath. The solution was filtered and $2 \mathrm{ml}$ were transferred into a $10 \mathrm{ml}$ volumetric flask. Solvent was vaporized under nitrogen steam. Afterwards the dry residues were dissolved in mobile phase $(10 \mathrm{ml})$. Warming up the samples was avoided in any step.

\subsubsection{Sample preparation for GC analysis}

The samples were ground in the same procedure as for HPLC preparation. $50 \mathrm{mg}$ of the grounded samples were extracted in $50 \mathrm{ml}$ mixture of n-hexane/ethyl acetate (9:1) for $40 \mathrm{~min}$ in the ultrasonic bath. After filtration, $9 \mathrm{ml}$ were mixed with $1 \mathrm{ml}$ triphenylamine being used as an internal standard. The mixture was finally transferred into a vial.

\subsection{Content calculation}

\subsubsection{Calculation of CBDA, CBD, THCA and $\Delta^{9}$-THC content for HPLC analysis}

Calibration curves of CBDA, CBD, THCA and $\Delta^{9}$-THC were prepared by diluting appropriate stock solutions. $1 \mathrm{mg}$ of each compound was diluted in $10 \mathrm{ml}$ mobile phase $(=100 \mu \mathrm{g} / \mathrm{ml})$. Calibration points in intervals of ten from $70 \mu \mathrm{g} / \mathrm{ml}$ to $10 \mu \mathrm{g} / \mathrm{ml}$ were chosen, and three points ( $5 \mu \mathrm{g} / \mathrm{ml}, 3 \mu \mathrm{g} / \mathrm{ml}$ and $1 \mu \mathrm{g} / \mathrm{ml}$ ) were added. The regression equations are shown in Table 1 .

\subsubsection{Calculation of CBD and $\Delta^{9}$-THC content for GC analysis}

$10 \mathrm{mg}$ of each compound were diluted in $50 \mathrm{ml}$-hexane/ethyl acetate (9:1). Calibration points from $180 \mu \mathrm{g} / \mathrm{ml}$ to $2 \mu \mathrm{g} / \mathrm{ml}$ were made $(180 ; 120 ; 100 ; 60 ; 20 ; 18 ; 12 ; 10 ; 6 ; 2 \mu \mathrm{g} / \mathrm{ml})$. The regression equations are shown in Table 1.

\section{Results and discussion}

In preliminary experiments, different mobile phases were applied in HPLC to separate and quantify cannabinoids. The first mobile phase consisted of triethylammonium phosphate $25 \mathrm{mM}$ $(\mathrm{pH}=3.0)$ and $\mathrm{ACN}$ with a ratio of 45:55. 
Table 1 Regression equation, correlation coefficient $\left(\mathrm{r}^{2}\right)$ of $\Delta^{9}$-THC, THCA, CBD and CBDA

\begin{tabular}{llcc}
\hline Compound name & Calibration curve & $\mathrm{r}^{2}$ & Linearity range $(\mu \mathrm{g} / \mathrm{ml})$ \\
\hline$\Delta^{9}$-THC & $\mathrm{y}=108.26 \mathrm{x}-26.831$ & 0.9991 & $1.0-70$ \\
$\Delta^{9}$-THC $*$ & $\mathrm{y}=0.0155 \mathrm{x}-0.035$ & 0.9993 & $2.0-180$ \\
THCA & $\mathrm{y}=45.346 \mathrm{x}-43.644$ & 0.9992 & $1.0-70$ \\
CBD & $\mathrm{y}=50.984 \mathrm{x}+7.565$ & 0.9999 & $1.0-70$ \\
CBD* & $\mathrm{y}=0.014 \mathrm{x}+0.011$ & 0.9854 & $2.0-180$ \\
CBDA & $\mathrm{y}=57.241 \mathrm{x}+9.846$ & 0.9999 & $1.0-70$ \\
\hline
\end{tabular}

Notes: *GC

$\Delta^{9}$-THC, THCA, CBD and CBDA standards were measured. The goal was an identification within 14 minutes, which was not possible with this mobile phase. Various changes in $\mathrm{pH}$ were not successful. By changing the ratio from 45:55 to 36:64, as Taschwer et al. described, retention times higher than 15 minutes were achieved [11]. In order to accomplish identification within 14 minutes, $\mathrm{pH}$-value was reduced from 3.0 to 2.7 .

A total of 36 different fresh cannabis samples were analyzed. All of them were seized by police, whereby it was unclear whether they represent CBD-, or THC-hemp. A comparison between HPLC-UV and GC-FID analysis was accomplished as follows: Samples were measured with both devices. Results are shown in Table 2 .

Table 2 Cannabinoids quantities (\%w/w) for the 37 samples investigated

\begin{tabular}{|c|c|c|c|c|c|c|c|c|}
\hline Sample & THC HPLC & THCA HPLC & THC+THCA HPLC & THC GC & CBD HPLC & CBDA HPLC & CBD+CBDA HPLC & CBD GC \\
\hline 1 & 0.37 & 1.12 & 1.49 & 1.35 & 0.15 & 0.00 & 0.15 & 0.14 \\
\hline 2 & 0.65 & 17.17 & 17.82 & 16.20 & 0.13 & 0.08 & 0.21 & 0.19 \\
\hline 3 & 0.53 & 6.16 & 6.69 & 6.08 & 0.00 & 0.29 & 0.29 & 0.26 \\
\hline 4 & 0.65 & 12.17 & 12.82 & 11.65 & 0.16 & 0.01 & 0.17 & 0.15 \\
\hline 5 & 0.82 & 9.45 & 10.27 & 9.34 & 0.14 & 0.04 & 0.19 & 0.17 \\
\hline 6 & 5.06 & 2.54 & 7.60 & 6.91 & 1.67 & 0.81 & 1.43 & 1.30 \\
\hline 7 & 0.75 & 4.50 & 5.25 & 4.77 & 0.09 & 0.05 & 0.28 & 0.25 \\
\hline 8 & 1.99 & 11.12 & 13.11 & 11.92 & 0.25 & 0.10 & 0.44 & 0.40 \\
\hline 9 & 1.07 & 5.56 & 6.63 & 6.03 & 0.04 & 0.02 & 0.34 & 0.31 \\
\hline 10 & 0.48 & 5.91 & 6.39 & 5.81 & 0.00 & 0.09 & 0.09 & 0.00 \\
\hline 11 & 7.83 & 1.20 & 9.03 & 8.21 & 0.19 & 0.04 & 0.23 & 0.21 \\
\hline 12 & 1.17 & 5.50 & 6.67 & 6.06 & 0.06 & 0.11 & 0.17 & 0.15 \\
\hline 13 & 2.95 & 4.86 & 7.81 & 7.10 & 0.09 & 0.06 & 0.15 & 0.14 \\
\hline 14 & 1.30 & 15.76 & 17.06 & 15.51 & 0.13 & 0.07 & 0.20 & 0.18 \\
\hline 15 & 0.09 & 1.46 & 1.55 & 1.41 & 0.00 & 0.08 & 0.08 & 0.07 \\
\hline 16 & 0.42 & 7.81 & 8.23 & 7.48 & 0.00 & 0.18 & 0.18 & 0.16 \\
\hline 17 & 0.61 & 1.65 & 2.26 & 2.05 & 0.21 & 0.01 & 0.22 & 0.20 \\
\hline 18 & 1.98 & 10.49 & 12.47 & 11.34 & 0.31 & 0.17 & 0.48 & 0.44 \\
\hline 19 & 0.98 & 12.03 & 13.01 & 11.83 & 0.12 & 0.11 & 0.23 & 0.21 \\
\hline 20 & 2.21 & 7.29 & 9.50 & 8.64 & 0.84 & 1.79 & 2.63 & 2.39 \\
\hline 21 & 2.00 & 13.28 & 15.28 & 13.89 & 1.61 & 1.12 & 2.73 & 2.48 \\
\hline 22 & 0.76 & 4.49 & 5.25 & 4.77 & 0.23 & 0.05 & 0.28 & 0.25 \\
\hline 23 & 1.96 & 8.80 & 10.76 & 9.78 & 0.26 & 0.13 & 0.39 & 0.35 \\
\hline 24 & 0.74 & 4.87 & 5.61 & 5.10 & 0.04 & 0.35 & 0.39 & 0.35 \\
\hline 25 & 0.10 & 0.58 & 0.68 & 0.62 & 0.54 & 6.39 & 6.93 & 6.30 \\
\hline 26 & 0.10 & 1.12 & 1.22 & 1.11 & 1.22 & 5.85 & 7.07 & 6.43 \\
\hline 27 & 0.14 & 1.38 & 1.52 & 1.38 & 1.87 & 6.60 & 8.47 & 7.70 \\
\hline 28 & 0.12 & 1.09 & 1.21 & 1.10 & 1.60 & 6.89 & 8.49 & 7.72 \\
\hline 29 & 0.13 & 1.43 & 1.56 & 1.42 & 1.19 & 10.04 & 11.23 & 10.21 \\
\hline 30 & 0.06 & 1.55 & 1.61 & 1.46 & 0.07 & 1.01 & 1.08 & 0.98 \\
\hline 31 & 0.07 & 2.06 & 2.13 & 1.94 & 0.19 & 1.78 & 1.97 & 1.79 \\
\hline 32 & 0.09 & 1.68 & 1.77 & 1.61 & 0.08 & 8.07 & 8.15 & 7.41 \\
\hline 33 & 0.09 & 2.34 & 2.43 & 2.21 & 0.35 & 6.89 & 7.24 & 6.58 \\
\hline 34 & 0.15 & 7.24 & 7.39 & 6.72 & 0.08 & 1.19 & 1.27 & 1.15 \\
\hline 35 & 0.52 & 0.91 & 1.43 & 1.30 & 2.41 & 3.82 & 6.23 & 5.66 \\
\hline 36 & 0.08 & 0.93 & 1.01 & 0.92 & 1.45 & 4.00 & 5.45 & 4.95 \\
\hline 37 & 0.05 & 0.07 & 0.12 & 0.11 & 0.42 & 0.69 & 1.11 & 1.01 \\
\hline
\end{tabular}

For HPLC, percentages of CBD and $\Delta^{9}$-THC and their corresponding acids were additionally displayed. Since a low CBD content is not relevant for prosecution, percentages below one percent were not shown. The $\Delta^{9}$-THC content was shown for each sample, because the $\Delta^{9}$ THC limit of $0.3 \%$ must not be exceeded in Austria. Sample \#25 was declared as CBD hemp, but it could be demonstrated with both HPLC and GC that the limit of $0.3 \%$ was exceeded. The corresponding chromatograms are shown in Figure 2. 

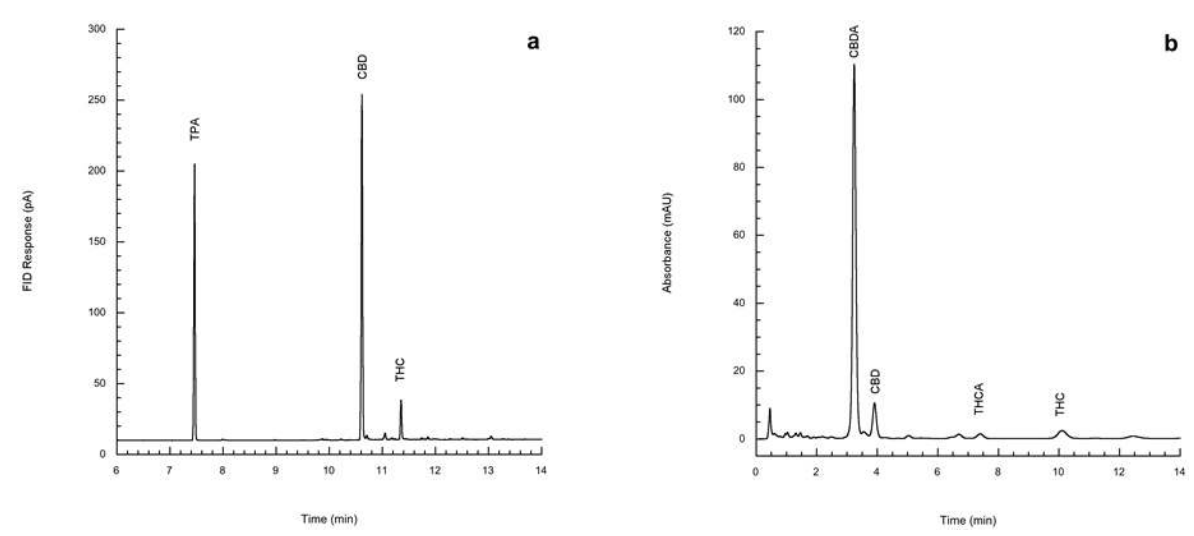

Figure 2 Chromatograms of Sample 25 by GC-FID (a) and HPLC-UV (b)

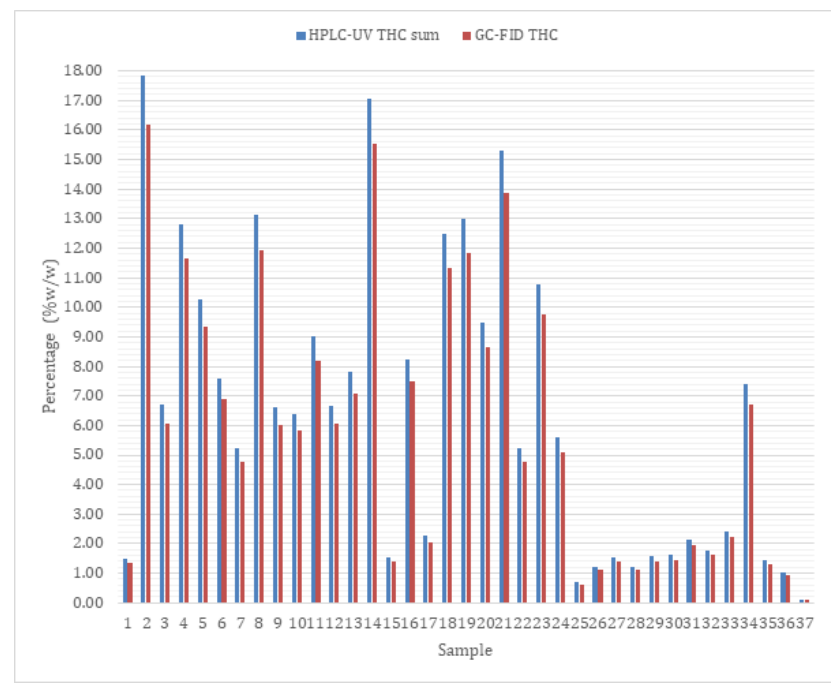

Figure 3 Comparison of $\Delta^{9}$-THC content between HPLC-UV and GC-FID

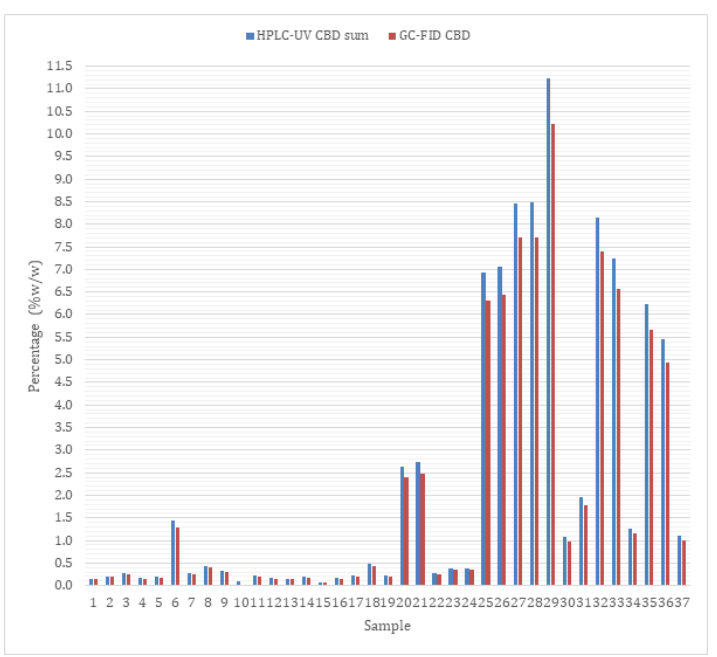

Figure 4 Comparison of CBD content between HPLC-UV and GC-FID

Gas chromatography is the most commonly used technique, which has been used earlier than HPLC. Regarding hemp analysis due to the high temperatures, However, cannabinoid acids decarboxylate to their corresponding cannabinoids, which makes detection of THCA and CBDA impossible. Since the total $\Delta^{9}$-THC content (higher $0.3 \%$ ) is relevant under criminal law only, the GC-FID method can be used successfully to determine the content of $\Delta^{9}$-THC 


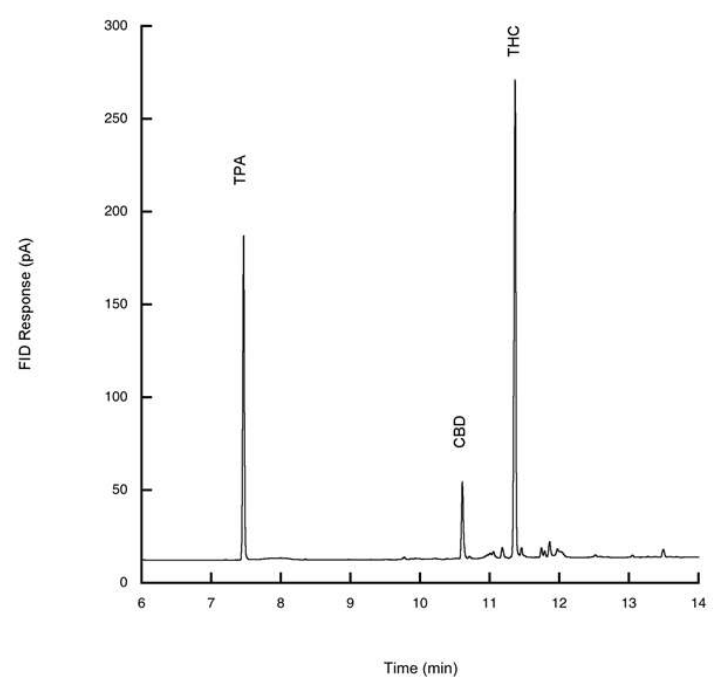

Figure 5 Chromatogram of a drug type (sample 34) by GC-FID

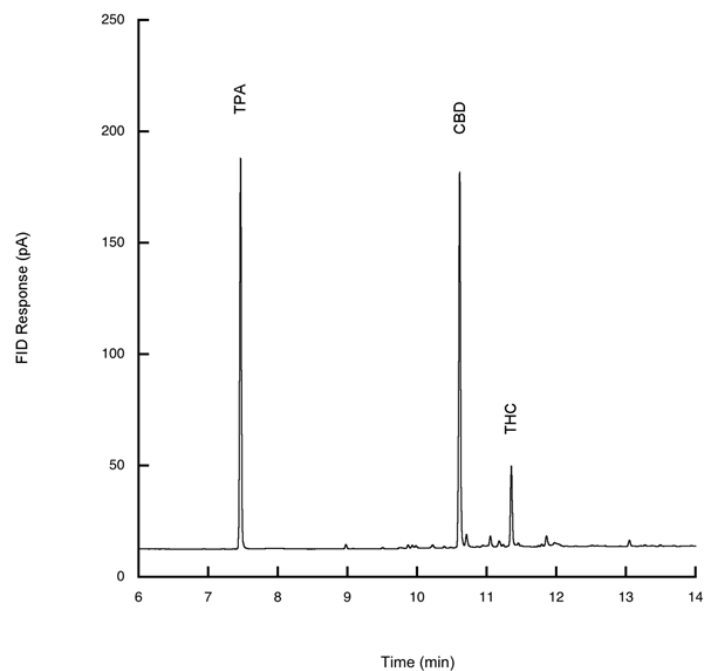

Figure 6 Chromatogram of a fiber type (sample 37) by GC-FID

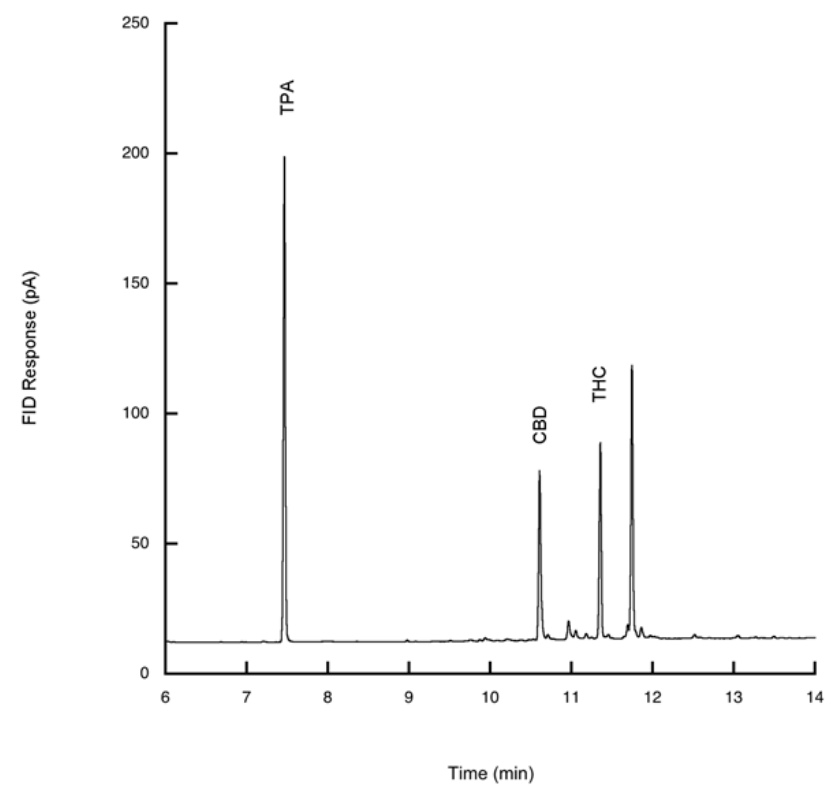

Figure 7 Chromatogram of an intermediate type (sample 31) by GC-FID 
in low $\Delta^{9}$-THC cannabis samples. In Austria, hemp is legal, if it complies to the European hempsort catalogue and if its content of THC is below $0.3 \%$. Since CBD is classified as novel food in the EU, the demand for CBD products is constantly increasing. Even if the content of $\mathrm{CBD}$ is not relevant under criminal law, vendors would like to monitor CBD content of their products.

Chemically, CBDA and CBD differ in the presence of a carboxyl group (Figure 1). From a pharmacological point of view, CBDA is considered the inactive form and gets decarboxylated by heat yielding the active form. To date, there are few publications about CBDA, one dealing with positive influence of CBDA on nausea and vomiting in rats [16]. Therefore, the ratio of $\mathrm{CBD}$ and $\mathrm{CBDA}$ in CBD products as well as the conversion rate of CBDA to CBD are essential.

Total results of HPLC and GC measurements are shown in Table 2. With HPLC, percentages of THCA and $\Delta^{9}$-THC as well as CBDA and CBD are displayed. The appropriate sums are compared to the percentages obtained by GC. For HPLC, percentages of $\Delta^{9}$-THC ranged between $0.11 \%$ and $15.04 \%$. For GC measurements, the results of the content determinations were comparable and ranged between $0.62 \%$ and $16.20 \%$. The total CBD content ranged from less than $0.1 \%$ to $9.90 \%$ for HPLC measurements and from less than $0.1 \%$ to $10.21 \%$ for GC experiments. A comparison of the contents of all samples is shown in Figure 3 and 4.

Following the definition of Sutipatanasomboon et al., with regard to the THC/CBD ratio, the cannabis plant can be divided into three categories, a drug type (ratio greater than 1) (Figure 5), a fiber type (ratio less than 1) (Figure 6) and an intermediate type (ratio close to 1) (Figure 7) [17].

Therefore all 37 measured cannabis samples can be assigned successfully: 26 samples count to drug type, 9 samples belong to the fiber-type and sample \#30 and \#31 can be assigned to the intermediate type. With this HPLC method, the simultaneous content determination of the phytocannabinoids CBD, CBDA, $\Delta^{9}$-THC and THCA was carried out within 12 minutes. Content of total $\Delta^{9}$-THC measured by GC, ranged between 0.11 and 16.20 percent. Mean percentage of THCA and $\Delta^{9}$-THC measured by HPLC was $83,35 \pm 17,67 \%$ and $16,65 \pm 17,67 \%$, respectively. Content of total CBD measured by GC, ranged between 0.00 and $10.21 \%$. Mean percentage of CBDA and CBD measured by HPLC was $58,31 \pm 33,61 \%$ and $39,47 \pm 33,92 \%$, respectively. However, these values are statistical and cannot explain the velocity of decomposition of both carboxy acids.

Overall, both methods allow an easy comparison and the small differences in percentages can be attributed to the inhomogeneity of plant materials.

\section{Conclusion}

Cannabis is not only the most abused, but the drug discussed most intense. There are advocates and opponents worldwide discussing the legalization of $\Delta^{9}$-THC-containing cannabis. Regardless of classification, research and development of quick and stable content determinations are essential. Various chromatographic methods such as TLC, GC-FID or HPLC can be used to separate the most important phytocannabinoids avoiding expensive devices. For this reason, HPLC and GC have become established rather than TLC; The latter technique only shows different spots and therefore a content determination is complex. The results of this study reveiled that identification of the two high abundant phytocannabinoids CBD and $\Delta^{9}$-THC is feasible within 14 minutes using GC-FID. Moreover, determination of the content of CBD, CBDA, $\Delta^{9}$-THC and THCA by HPLC-UV is possible within 12 minutes.

\section{References}

[1] Turner CE, Elsohly MA and Boeren EG. Constituents of cannabis sativa L. XVII. A Review of the natural constituents. Journal of Natural Products, 1980, 43(2): 169-234. https://doi.org/10.1021/np50008a001

[2] Elsohly MA and Slade D. Chemical constituents of marijuana: the complex mixture of natural cannabinoids. Life Sciences, 2005, 78(5): 539-548. https://doi.org/10.1016/j.lfs.2005.09.011

[3] European Monitoring Centre for Drugs and Drug Addiction. European Drug Report. 2019, n.d., November 10th, 2020. https://www.emcdda.europa.eu/system/files/publications/11364/20191724_TDAT19001ENN_PDF. pdf

[4] EMCDDA. Low-THC cannabis products being sold in the EU - key legal issues. 2018, n.d., November 10th, 2020. https://www.emcdda.europa.eu/news/2018/low-thc-cannabis-products-being-sold-in-the-EU\% E2\%80\%93key-legal-issues_en 
[5] Fischedick JT, Glas R, Hazekamp A, et al. A Qualitative and Quantitative HPTLC Densitometry Method for the Analysis of Cannabinoids in Cannabis sativa L. Phytochemical Analysis, 2009, 20(5): 421-426. https://doi.org/10.1002/pca.1143

[6] Yotoriyama M, Ishiharajima E, Kato Y, et al. Identification and Determination of Cannabinoids in both Commercially Available and Cannabis Oils Stored Long Term. Journal of Health Science, 2005, 51(4): 483-487. https://doi.org/10.1248/jhs.51.483

[7] Cole BB. A preliminary study of the analysis of Cannabis by supercritical fluid chromatography with atmospheric pressure chemical ionisation mass spectroscopic detection. Forensic Science Unit, 1997, 37: 91-97.

[8] Jambo H, Dispas A, Avohou HT, et al. Implementation of a generic SFC-MS method for the quality control of potentially counterfeited medicinal cannabis with synthetic cannabinoids. Journal of Chromatography B, 2018, 1092: 332-342. https://doi.org/10.1016/j.jchromb.2018.05.049

[9] Wang M, Wang Y, Avula B, et al. Quantitative Determination of Cannabinoids in Cannabis and Cannabis Products Using Ultra-High-Performance Supercritical Fluid Chromatography and Diode Array / Mass Spectrometric Detection. Journal of Forensic Sciences, 2017, 62(3): 602-611. https://doi.org/10.1111/1556-4029.13341

[10] Ibrahim EA, Gul W, Gul SW, et al. Determination of Acid and Neutral Cannabinoids in Extracts of Different Strains of Cannabis sativa Using GC-FID. Planta Medica, 2018, 84(4): 250-259. https://doi.org/10.1055/s-0043-124088

[11] Taschwer M and Schmid MG. Determination of the relative percentage distribution of THCA and D9-THC in herbal cannabis seized in Austria - Impact of different storage temperatures on stability. Forensic Science International, 2015, 254: 167-171. https://doi.org/10.1016/j.forsciint.2015.07.019

[12] Gul W, Gul SW, Radwan MM, et al. Determination of 11 Cannabinoids in Biomass and Extracts of Different Varieties of Cannabis Using High-Performance Liquid Chromatography. Journal of AOAC International, 2015, 98(6): 1523-1528. https://doi.org/10.5740/jaoacint.15-095

[13] Wang YH, Avula B, Elsohly M, et al. Quantitative Determination of $\Delta$ 9-THC, CBG, CBD, Their Acid Precursors and Five Other Neutral Cannabinoids by UHPLC-UV-MS. Planta Medica, 2017: 84(4): 260-266. https://doi.org/10.1055/s-0043-124873

[14] Citti C, Battisti M, Braghiroli D, et al. A Metabolomic Approach Applied to a Liquid Chromatography Coupled to High-Resolution Tandem Mass Spectrometry Method (HPLC-ESI-HRMS/MS) Towards the Comprehensive Evaluation of the Chemical Composition of Cannabis Medicinal Extracts. Phytochemical Analysis, 2018, 29(2): 144-155. https://doi.org/10.1002/pca.2722

[15] Backer B De, Debrus B, Lebrun P, et al. Innovative development and validation of an HPLC/DAD method for the qualitative and quantitative determination of major cannabinoids in cannabis plant material. Journal of Chromatography B, 2009, 877(32): 4115-4124. https://doi.org/10.1016/j.jchromb.2009.11.004

[16] Bolognini D, Rock EM, Cluny NL, et al. Cannabidiolic acid prevents vomiting in Suncus murinus and nausea-induced behaviour in rats by enhancing 5-HT1A receptor activation. British Journal of Pharmacology, 2013, 168(6): 1456-1470. https://doi.org/10.1111/bph.12043

[17] Sutipatanasomboon A and Panvisavas N. Discrimination of "fiber-type" and "drug-type" Cannabis sativa L. by fluorescent duplex PCR. Forensic Science International: Genetics Supplement Series, 2011, 3(1): e522-e523. https://doi.org/10.1016/j.fsigss.2011.10.008 